\title{
Triglicerideos sangüíneos e composição química da carne de codornas alimentadas com bixina e niacina suplementar
}

\author{
Newton Tavares Escocard de Oliveira ${ }^{(1)}$, José Brandão Fonseca( ${ }^{(1)}$, Rita da Trindade Ribeiro Nobre Soares ${ }^{(1)}$ \\ e Karla Silva Ferreira ${ }^{(1)}$
}

(1)Universidade Estadual do Norte Fluminense, Av. Alberto Lamego, № 2000, Parque Califórnia, CEP 28013-600 Campos dos Goytacazes, RJ. E-mail: newtonescocard@hotmail.com, jfonseca@uenf.br, rnobre@uenf.br, karlasf@uenf.br

\begin{abstract}
Resumo - O objetivo deste trabalho foi avaliar o efeito de bixina do colorífico e niacina suplementar em rações, nos níveis plasmáticos de triglicerídeos e lipoproteínas de densidade muito baixa, na gordura da carne de peito, de coxa e sobrecoxa, e na carcaça de codornas. Utilizaram-se 240 codornas japonesas (Coturnix japonica) machos, em delineamento experimental inteiramente casualizado, com quatro tratamentos, cinco repetições e 12 codornas por unidade experimental. Os tratamentos foram: ração referência, à base de milho e farelo de soja, sem inclusão de colorífico e de niacina suplementar; ração com 4,5\% de colorífico; ração com 0,08\% de niacina suplementar e ração com $4,5 \%$ de colorífico e $0,08 \%$ de niacina suplementar. Não houve efeito de tratamento nos níveis plasmáticos de triglicerídeos e lipoproteínas de densidade muito baixa e nos teores de extrato etéreo na carne de coxa e sobrecoxa, e na carcaça das codornas. No $49^{\circ}$ dia de idade, as codornas que receberam rações com $0,08 \%$ de niacina suplementar apresentaram maior teor de gordura na carne de peito $(1,50 \%)$ do que as codornas alimentadas com a ração referência $(0,85 \%)$. O uso de bixina do colorífico e niacina suplementar, em rações, não reduz os níveis de gordura no sangue, carne e carcaça de codornas japonesas machos.
\end{abstract}

Termos para indexação: Coturnix japonica, carcaça, colorífico, gordura, lipoproteínas.

\section{Plasma triglycerides and chemical composition of quail's meat fed on bixin and supplementary niacin}

\begin{abstract}
The objective of this work was to assess the effect of spice's bixin and supplementary niacin on diets in the plasmatic levels of triglyceride and very low-density lipoprotein, and in the fat of breast, drumstick and thigh meat and carcass of japanese quails (Coturnix japonica). Two hundred and forty japanese male quails were used in a completely randomized design, with four treatments, five replicates and 12 quails per experimental unit. The treatments were: reference diet with corn and soybean meal, without spice or supplementary niacin; diet with $4.5 \%$ spice; diet with $0.08 \%$ supplementary niacin and diet with $4.5 \%$ spice and $0.08 \%$ supplementary niacin. The treatments had no effect upon triglyceride and very low-density lipoprotein levels in plasma, as well as on ether extract contents in the drumstick and thigh meat and carcass of the quails. On the $49^{\text {th }}$ day of age, quails that received rations with $0.08 \%$ supplementary niacin had higher fat contents in the breast meat (1.50\%) than quails fed with reference ration (0.85\%). The addition of spice's bixin and supplementary niacin to the rations do not reduce the fat levels in plasma, meat and carcass of japanese male quails.
\end{abstract}

Index terms: Coturnix japonica, carcass, fat, lipoproteins, spice.

\section{Introdução}

A avaliação do valor calórico dos alimentos pode ser feita pela mensuração da quantidade de energia bruta (EB) liberada na oxidação dos nutrientes. Segundo Rostagno et al. (2000), um grama de gordura de aves apresenta 9,33 kcal de EB, valor calórico 2,4 vezes maior do que 3,87 kcal de EB, obtido na oxidação de um grama de amido, fonte quase exclusiva de carboidrato.
Assim, a produção de aves com pouco acúmulo de gordura pode contribuir para reduzir a ingestão de calorias nas dietas humanas e para controlar os níveis de triglicerídeos sangüíneos, considerados fatores de risco para as doenças coronarianas arteriais (Gotto Junior, 1998).

Em frangos de corte e perus alimentados à vontade, baixos níveis plasmáticos de lipoproteínas de densidade muito baixa (VLDL) foram bem correlacionados 
( $\mathrm{r}=0,6$ a 0,7$)$ ao baixo conteúdo de gordura corporal (Griffin et al., 1999). Correlação negativa tem sido encontrada entre os conteúdos de proteína e de gordura na carcaça de frangos (Silva et al., 2004).

Segundo Kessler \& Snizek Júnior (2001), aves mais magras apresentaram menor concentração plasmática de VLDL e menor atividade da lipase lipoprotéica, enzima que catalisa a hidrólise de triglicerídeos do núcleo das VLDL em ácidos graxos e glicerol. No tecido adiposo, os ácidos graxos são reesterificados e armazenados como triglicerídeos.

O acúmulo de gordura em aves depende, em sua maior parte, da síntese e secreção de lipoproteínas pelo fígado, já que a síntese de ácidos graxos é muito limitada no tecido adiposo. A síntese e secreção de lipoproteínas é dependente, principalmente, da disponibilidade de carboidratos nas rações, que darão origem a moléculas de acetil-CoA, pois a contribuição dos lipídeos nas rações é pequena (Hermier, 1997).

Em cortes sem pele e osso, a carne de peito de frangos de corte apresentou de 1,6 a 2,4\% de gordura (Kessler \& Snizek Júnior, 2001). Codornas japonesas machos apresentaram 4\% de extrato etéreo (EE) em carne de peito, no 35o dia, 7,1\% no 49을 dia de idade (Yalçin et al., 1995), e 6,98\% de EE na carcaça (matéria natural) no 35o dia de idade (Kirkpinar \& Oguz, 1995).

O efeito hipolipidêmico da bixina, presente no colorífico, tem sido atribuído à ação ativadora da lipase lipoprotéica (Lima et al., 1999). Para o ácido nicotínico, o efeito na redução dos níveis de triglicerídeos sangüíneos decorre da capacidade de inibir a lipólise do tecido adiposo, de reduzir a esterificação dos triglicerídeos no fígado e de aumentar a atividade da lipase lipoprotéica (Hardman \& Limbird, 1996).

Depois de três meses e em relação ao grupo que recebeu ração, ratos alimentados com ração diária com $700 \mathrm{mg}$ de corante e $28 \%$ de bixina tiveram redução $(p \leq 0,05)$ de 43,65\% dos níveis de triglicerídeos séricos (Souza, 2001).

Depois de 43 horas da indução de hiperlipidemia com Triton ( $\mathrm{T})$, ratos que receberam ração comercial (R) + T + 5 mg de ácido nicotínico por quilograma de peso corporal, por via intraperitoneal, apresentaram 104,56 mg de triglicerídeo por decilitro de soro, valor inferior $(p \leq 0,05)$ ao apresentado por ratos tratados com $\mathrm{R}+\mathrm{T}$, que foi de $311,36 \mathrm{mg} \mathrm{dL}^{-1}$. Os ratos tratados com ração apresentaram 162,30 $\mathrm{mg} \mathrm{dL}^{-1}$ (Santos et al., 1999).

Com hiperlipidemia induzida por $1 \%$ de colesterol (COL) e 0,1\% de ácido cólico (AC) na ração (R) diária, durante 28 dias, coelhos que receberam $\mathrm{R}+\mathrm{COL}+\mathrm{AC}$ e a dose oral (em cápsula) diária de 0,01 mol de bixina por quilograma de peso corporal apresentaram 228,79 mg de triglicerídeo por decilitro, valor superior $(\mathrm{p} \leq 0,05)$ a $113,78 \mathrm{mg} \mathrm{dL}^{-1}$, obtido por coelhos que receberam somente ração (Lima et al., 2001).

Este trabalho teve o objetivo de avaliar o efeito de bixina do colorífico e niacina suplementar em rações, nos níveis de triglicerídeos e lipoproteínas de densidade muito baixa no sangue, na gordura da carne de peito, coxa e sobrecoxa e na carcaça de codornas japonesas machos, sob condições normais de alimentação.

\section{Material e Métodos}

O experimento foi realizado em junho de 2003, no Campo Experimental da Universidade Estadual do Norte Fluminense (Uenf), localizada no Município de Campos dos Goytacazes.

Foram utilizadas 240 codornas japonesas (Coturnix japonica) machos, em delineamento experimental inteiramente casualizado, com quatro tratamentos, cinco repetições e 12 codornas por unidade experimental (boxe de madeira e tela, de 2,05 $\mathrm{m}$ de comprimento $\mathrm{x}$ 1,75 m de largura x 1,77 m de altura).

Os tratamentos consistiram de ração referência, à base de milho e farelo de soja, sem inclusão de colorífico e niacina suplementar; ração com 4,5\% de colorífico; ração com $0,08 \%$ de niacina suplementar; e ração com $4,5 \%$ de colorífico e $0,08 \%$ de niacina suplementar.

As codornas com idade inicial de 21 dias foram alojadas em galpão de alvenaria, com 20 boxes, e receberam água e ração à vontade, em bebedouros do tipo copo de pressão e comedouros do tipo bandeja, além de serem submetidas a 11 horas de luz natural diária, a fim de evitar o canibalismo. Foi usada casca de arroz polido, como material absorvente da umidade da cama.

$\mathrm{Na}$ fase inicial (de 1 a 21 dias), as codornas receberam ração comercial com um nível mínimo de $28 \%$ de proteína bruta e $0,70 \%$ de fósforo, nível máximo de 1,50\% de cálcio, e foi suplementada com 48 mg de niacina por quilograma de ração.

A partir do 21ํ dia de idade, as codornas receberam as rações experimentais, cujas formulações foram baseadas em valores de matéria seca e proteína bruta do milho, farelo de soja e colorífico, determinados previamente, segundo Silva \& Queiroz (2002). As análises de cálcio e fósforo total desses alimentos foram realizadas segundo Silva \& Queiroz (2002) (Tabela 1). 
Nas formulações das rações experimentais, foram utilizados os valores de energia metabolizável aparente corrigida pelo balanço de nitrogênio (EMAn), em quilocaloria por quilograma de matéria natural, do milho (3.122), farelo de soja (2.651), colorífico (3.102) e óleo de soja degomado (7.940), determinados previamente em ensaio de digestibilidade, utilizando-se codornas japonesas fêmeas. O valor energético do óleo de soja refinado foi extrapolado do valor de EMAn, obtido com o teste do óleo de soja degomado.

Exceto os nutrientes cujos valores foram mencionados, todas as rações foram formuladas de acordo com as composições químicas dos ingredientes apresentados por Rostagno et al. (2000), e adequadas às exigências nutricionais, para codornas japonesas, do National Research Council (1994), à exceção dos níveis de proteína bruta (Tabela 2).

Nos períodos de 21 a 35 e 35 a 49 dias de idade, foram avaliados: ganho de peso (g), consumo de ração (g) e conversão alimentar ( $\mathrm{g} \mathrm{g}^{-1}$ ). No 35o e 49o dia de idade, foram avaliados: peso (g); triglicerídeos e lipoproteínas de densidade muito baixa no plasma sangüíneo ( $\left.\mathrm{mg} \mathrm{dL}^{-1}\right)$, e matéria seca (\%); extrato etéreo (\%) e proteína bruta (\%) da carne de peito, da carne de coxa e sobrecoxa e da carcaça.

Para determinação dos triglicerídeos e das lipoproteínas de densidade muito baixa no plasma sangüíneo, foram coletados, no 35o e 49o dia de idade, de 2 a $3 \mathrm{~mL}$ de sangue por codorna, em duas codornas escolhidas aleatoriamente, de cada unidade experimental, depois de um período de jejum alimentar de 12 horas.

As amostras de sangue foram drenadas individualmente para tubos de vidro esterilizados, e centrifugadas a $3.000 \mathrm{rpm}$, por cinco minutos. Os plasmas foram reunidos dois a dois, por repetição, e utilizados para determinar os níveis de triglicerídeos (T), utilizando-se o método denominado química seca. Os teores de lipoproteínas de densidade muito baixa foram estimados a partir dos valores de T, utilizando-se

Tabela 1. Composição bromatológica (\%) de ingredientes utilizados nas rações experimentais, expressa na base da matéria natural.

\begin{tabular}{lcccc}
\hline Ingrediente & $\begin{array}{c}\text { Matéria } \\
\text { seca }\end{array}$ & $\begin{array}{c}\text { Proteína } \\
\text { bruta }\end{array}$ & Cálcio & $\begin{array}{c}\text { Fósforo } \\
\text { total }\end{array}$ \\
\hline Milho & 86,77 & 7,99 & 0,04 & 0,32 \\
Farelo de soja & 87,77 & 46,81 & 0,29 & 0,63 \\
Colorífico & 88,30 & 7,00 & 0,05 & 0,15 \\
\hline
\end{tabular}

a equação (VLDL = T/5) de Friedewald et al. (1972), citado por Hammad et al. (1998).

Depois da coleta do sangue, as codornas foram sangradas; foram descartados os metatarsos e os dedos (corte na articulação tíbio-társica), a pele e as penas (corte superficial realizado no dorso das codornas) e parte das asas (corte na articulação úmero-cubital); foram evisceradas manualmente (corte transversal da cloaca e corte ventral, entre a ponta do esterno e o abdômen), limpas e lavadas em água corrente.

A seguir, as carcaças foram reunidas por repetição, embaladas, identificadas, mergulhadas em gelo picado, desembaladas, gotejadas, reembaladas, reidentificadas e congeladas para análises posteriores.

Com antecedência de 48 horas à manipulação, as carcaças foram degeladas completamente em geladeira a $4^{\circ} \mathrm{C}$, e as coxas e sobrecoxas e o peito de cada codorna foram separados nas articulações e reunidos por parte e repetição.

Tabela 2. Composição porcentual e valores nutricionais calculados das rações experimentais.

\begin{tabular}{lrrrr}
\hline Ingrediente (\%) & Ração 1 & Ração 2 & Ração 3 & Ração 4 \\
\hline Milho & 62,63 & 57,89 & 62,47 & 57,73 \\
Farelo de soja & 33,96 & 34,10 & 33,99 & 34,13 \\
DL-Metionina & 0,01 & 0,01 & 0,01 & 0,01 \\
Fosfato bicálcico & 0,87 & 0,88 & 0,87 & 0,88 \\
Calcário & 1,19 & 1,18 & 1,19 & 1,18 \\
Cloreto de sódio & 0,27 & 0,27 & 0,27 & 0,27 \\
Inerte & 0,16 & 0,16 & 0,16 & 0,16 \\
Óleo de soja refinado & 0,51 & 0,61 & 0,56 & 0,66 \\
Suplemento mineral vitamínico ${ }^{(1)}$ & 0,40 & 0,40 & 0,40 & 0,40 \\
Colorífico & - & 4,50 & - & 4,50 \\
Nicotinamida em pón ${ }^{(2)}$ & - & - & 0,08 & 0,08 \\
\hline Nutrientes calculados (\%) & \multicolumn{4}{c}{} \\
\hline Proteína bruta & 21,00 & 21,00 & 21,00 & 21,00 \\
EMAn ${ }^{(3)}$ & 2.900 & 2.900 & 2.900 & 2.900 \\
Extrato etéreo & 3,14 & 3,23 & 3,19 & 3,28 \\
Metionina + cistina & 0,84 & 0,84 & 0,84 & 0,84 \\
Metionina & 0,50 & 0,50 & 0,50 & 0,50 \\
Lisina & 1,10 & 1,10 & 1,10 & 1,10 \\
Treonina & 0,81 & 0,81 & 0,81 & 0,81 \\
Cálcio & 0,80 & 0,80 & 0,80 & 0,80 \\
Fósforo disponível & 0,30 & 0,30 & 0,30 & 0,30 \\
Sódio & 0,15 & 0,15 & 0,15 & 0,15 \\
\hline
\end{tabular}

(1)Usado na postura e na reprodução inicial completa - quantidades em 1.000 g: vit. A, 3.750 .000 UI; vit. $D_{3}, 750.000$ UI; vit. E, $7.500 \mathrm{mg}$; vit. $K_{3}, 1.000 \mathrm{mg}$; vit. $\mathrm{B}_{1}, 750 \mathrm{mg}$; vit. $\mathrm{B}_{2}, 1.500 \mathrm{mg}$; vit. $\mathrm{B}_{6}, 1.500 \mathrm{mg}$; vit. $\mathrm{B}_{12}, 7.500 \mu \mathrm{g}$; niacina, $10.000 \mathrm{mg}$; ácido pantotênico, $3.750 \mathrm{mg}$; biotina, $30 \mathrm{mg}$; ácido fólico, $375 \mathrm{mg}$; colina, $10.000 \mathrm{mg}$; metionina, 400.000 mg; Se, 45 mg; I, 175 mg; Fe, 12.525 mg; Cu, 2.500 mg; Mn, $19.500 \mathrm{mg}$; Zn, $13.750 \mathrm{mg}$; avilamicina, $15.000 \mathrm{mg}$; nicarbazina, $12.500 \mathrm{mg}$; narasin, $10.000 \mathrm{mg}$; BHT, $500 \mathrm{mg}$; vit. C, $12.500 \mathrm{mg}$. (2)Nicotinamida com teor de $100 \%$ de pureza; $800 \mathrm{mg} \mathrm{kg}^{-1}$ de ração $=20$ vezes a exigência nutricional de niacina para codornas japonesas (National Research Council, 1994). ${ }^{(3)}$ Energia metabolizável aparente corrigida por retenção de $\mathrm{N}$. 
A carne do peito, da coxa e da sobrecoxa foi retirada, identificada, pesada, colocada em estufa a $105^{\circ} \mathrm{C}$ por 24 horas, esfriada à temperatura ambiente, pesada, moída, armazenada e identificada para posteriores análises químicas de matéria seca definitiva, extrato etéreo e proteína bruta, de acordo com Silva \& Queiroz (2002). As tíbias, os fêmures e os esternos foram descartados, e as carcaças incompletas (com ossos) foram submetidas ao mesmo procedimento adotado para a carne do peito e da coxa e sobrecoxa.

Os efeitos da inclusão de bixina do colorífico e de niacina suplementar, sobre as variáveis, foram verificados pela análise de variância, e suas médias foram comparadas pelo teste de Tukey a 5\% de probabilidade. Todas as análises estatísticas foram efetuadas usandose o Sistema de Análises Estatísticas e Genéticas (SAEG) (Universidade Federal de Viçosa, 1997).

\section{Resultados e Discussão}

Não foi observado efeito significativo $(p>0,05)$ de tratamentos sobre as variáveis de desempenho, nos períodos de 21 a 35 e 35 a 49 dias de idade das codornas japonesas machos (Tabela 3).

Esses resultados indicam que não houve efeito deletério no uso de $4,5 \%$ de colorífico e $0,08 \%$ de niacina suplementar sobre o consumo de ração, ganho de peso, conversão alimentar e peso das codornas.

Neste trabalho, o peso corporal médio das codornas foi de $103 \mathrm{~g}$ aos 35 dias e $121 \mathrm{~g}$ aos 49 dias de idade.

Tabela 3. Consumo de ração (CR), ganho de peso (GP) e conversão alimentar (CA) de codornas japonesas machos no período de 21 a 35 e 35 a 49 dias de idade e peso (P) ao final dos períodos ${ }^{(1)}$.

\begin{tabular}{|c|c|c|c|c|}
\hline Tratamento $^{(2)}$ & $\begin{array}{c}\text { CR } \\
\text { (g por ave) }\end{array}$ & $\begin{array}{c}\text { GP } \\
\text { (g por ave) }\end{array}$ & $\begin{array}{c}\mathrm{CA} \\
\left(\mathrm{g} \mathrm{g}^{-1}\right)\end{array}$ & $\begin{array}{c}\mathrm{P} \\
\text { (g por ave) }\end{array}$ \\
\hline & \multicolumn{4}{|c|}{ Período de 21 a 35 dias } \\
\hline Ração & $183,5 \pm 1,51$ & $37,87 \pm 0,72$ & $4,85 \pm 0,07$ & $102,4 \pm 0,72$ \\
\hline Ração + colorífico & $182,1 \pm 1,63$ & $38,47 \pm 0,79$ & $4,74 \pm 0,11$ & $102,6 \pm 1,07$ \\
\hline Ração + NS & $187,3 \pm 3,55$ & $40,11 \pm 0,97$ & $4,68 \pm 0,10$ & $104,0 \pm 0,67$ \\
\hline Ração + colorífico + NS & $178,6 \pm 2,40$ & $38,03 \pm 1,72$ & $4,73 \pm 0,18$ & $103,3 \pm 1,60$ \\
\hline CV $(\%)$ & 2,95 & 6,50 & 5,81 & 2,35 \\
\hline \multirow[t]{2}{*}{ QM resíduo } & 29,1950 & 6,3109 & 0,0762 & 5,8570 \\
\hline & \multicolumn{4}{|c|}{ Período de 35 a 49 dias } \\
\hline Ração & $204,9 \pm 4,03$ & $18,16 \pm 1,62$ & $11,55 \pm 0,75$ & $121,7 \pm 1,65$ \\
\hline Ração + colorífico & $196,3 \pm 2,16$ & $16,77 \pm 1,26$ & $11,97 \pm 0,91$ & $120,5 \pm 0,75$ \\
\hline Ração + NS & $204,9 \pm 2,66$ & $16,47 \pm 1,12$ & $12,64 \pm 0,77$ & $122,9 \pm 1,65$ \\
\hline Ração + colorífico + NS & $200,4 \pm 4,49$ & $17,10 \pm 1,20$ & $11,90 \pm 0,71$ & $120,3 \pm 0,84$ \\
\hline $\mathrm{CV}(\%)$ & 3,85 & 17,14 & 14,65 & 2,39 \\
\hline QM resíduo & 60,1135 & 8,6177 & 3,0989 & 8,3876 \\
\hline
\end{tabular}

Entretanto, codornas japonesas machos com 35 e 49 dias de idade atingiram o peso corporal de 144 e 166 g, respectivamente (Yalçin et al., 1995).

Não foi observado efeito significativo $(p>0,05)$ de tratamentos sobre os níveis de triglicerídeos e lipoproteínas de densidade muito baixa, no sangue das codornas, no 35으 e 49o dia de idade (Tabela 4).

A bixina do colorífico e a niacina suplementar não exerceram atividade hipolipidêmica sobre o perfil lipídico, no sangue de codornas que receberam alimentação sem indução de hiperlipidemia. Esses resultados não corroboram os obtidos por Souza (2001), que encontrou redução significativa nos níveis de triglicerídeos no sangue de ratos que receberam, diariamente, ração com $700 \mathrm{mg}$ de corante industrial com $28 \%$ de bixina, em relação ao tratamento com ração, e também não concordam com os resultados de Santos et al. (1999), que verificaram um decréscimo no valor de triglicerídeos no sangue de ratos que receberam ração, triton e $5 \mathrm{mg}$ de ácido nicotínico por quilograma de peso corporal (104,56 $\left.\mathrm{mg} \mathrm{dL}^{-1}\right)$, em relação a ratos que receberam somente ração $\left(162,30 \mathrm{mg} \mathrm{dL}^{-1}\right)$.

Todavia, Lima et al. (2001) verificaram que coelhos tratados com ração, 1\% de colesterol, 0,1\% de ácido cólico e 0,01 mol de bixina por quilograma de peso corporal apresentaram maior valor $(\mathrm{p} \leq 0,05)$ de triglicerídeo no sangue (228,79 $\mathrm{mg} \mathrm{dL}^{-1}$ ) em relação a coelhos que receberam somente ração $\left(113,78 \mathrm{mg} \mathrm{dL}^{-1}\right)$.

Observou-se que os valores médios de triglicerídeos e lipoproteínas de densidade muito baixa, no 49o dia, foram superiores aos valores médios de triglicerídeos e lipoproteínas de densidade muito baixa no 35o dia (Tabela 4). Os aumentos médios dos valores de triglicerídeos e lipoproteínas de densidade muito baixa foram de 86,2, 79,0, 105,8 e 75,8\%, nos tratamentos com ração, ração e colorífico, ração e niacina suplementar e ração, colorífico e niacina suplementar, respectivamente.

Tabela 4. Triglicerídeos (T) e lipoproteínas de densidade muito baixa (VLDL), em $\mathrm{mg} \mathrm{dL}^{-1}$, no sangue de codornas japonesas machos aos 35 e 49 dias de idade ${ }^{(1)}$.

\begin{tabular}{lcccc}
\hline Tratamento $^{(2)}$ & T 35 & VLDL 35 & T 49 & VLDL 49 \\
\hline Ração & $40,6 \pm 5,11$ & $8,12 \pm 1,02$ & $75,6 \pm 8,04$ & $15,12 \pm 1,61$ \\
Ração + colorífico & $39,0 \pm 2,39$ & $7,80 \pm 0,48$ & $69,8 \pm 4,20$ & $13,96 \pm 0,84$ \\
Ração + NS & $34,6 \pm 3,01$ & $6,92 \pm 0,60$ & $71,2 \pm 11,47$ & $14,24 \pm 2,29$ \\
Ração + colorífico + NS & $38,0 \pm 2,35$ & $7,60 \pm 0,47$ & $66,8 \pm 4,91$ & $13,36 \pm 0,98$ \\
\hline CV (\%) & 20,02 & 20,02 & 24,34 & 24,34 \\
QM resíduo & 58,0250 & 2,3210 & 297,4750 & 11,8990 \\
\hline
\end{tabular}

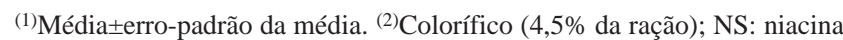
suplementar (0,08\% da ração). 
Segundo Hermier (1997), a transformação hepática crescente de carboidratos oriundos da ração em lipídeos sangüíneos pode elevar os níveis de triglicerídeos e de lipoproteínas de densidade muito baixa.

Não foi observado efeito significativo $(\mathrm{p}>0,05) \mathrm{de}$ tratamentos sobre os teores de matéria seca e proteína bruta, na carne de peito das codornas com 35 e 49 dias de idade. O mesmo resultado ocorreu em relação aos níveis de extrato etéreo, no 35 dia de idade. Houve efeito significativo $(\mathrm{p} \leq 0,05)$ de tratamento sobre os níveis de extrato etéreo, no 49ํㅡㅁ. Codornas alimentadas com ração e niacina suplementar e ração, colorífico e niacina suplementar apresentaram níveis mais elevados de extrato etéreo na carne de peito do que codornas que receberam ração, e ração e colorífico (Tabela 5).

Segundo Hardman \& Limbird (1996), o ácido nicotínico tem capacidade de inibir a lipase hormônio sensível, enzima responsável pela lipólise do tecido adiposo, e de aumentar a atividade da lipase lipoprotéica. Aves mais magras têm apresentado menor atividade da lipase lipoprotéica (Kessler \& Snizek Júnior, 2001), e baixos níveis de lipoproteínas de densidade muito baixa, no sangue, têm sido bem correlacionados com baixo conteúdo de gordura corporal (Griffin et al., 1999). Considerando-se esses relatos, os resultados obtidos evidenciam que a dosagem de $0,08 \%$ de niacina suplementar na ração alterou o metabolismo lipídico na carne de peito de codornas com 49 dias de idade.

No 49음 dia de idade (Tabela 5), os valores de matéria seca $(24,2 \%)$ e extrato etéreo $(1,33 \%)$ do tratamento ração, colorífico e niacina suplementar foram $18 \%$ e $81,3 \%$ inferiores, respectivamente, aos valores de matéria seca $(29,5 \%)$ e extrato etéreo $(7,1 \%)$ na carne de peito, obtidos por Yalçin et al. (1995). Neste trabalho, o teor protéico (20,5\%) foi 5,7\% superior ao valor obtido $(19,4 \%)$ por Yalçin et al. (1995), e o valor de 1,33\% de extrato etéreo foi similar ao intervalo de valores $(1,6 \%$ a 2,4\%) de gordura da carne de peito de frangos de corte de ambos os sexos, em cortes sem pele e sem osso, relatado por Kessler \& Snizek Júnior (2001).

Não foi observado efeito significativo $(p>0,05)$ de tratamento, sobre os teores de matéria seca e extrato etéreo, na carne de coxa e sobrecoxa de codornas japonesas machos, com 35 e 49 dias de idade. O mesmo resultado ocorreu em relação aos níveis de proteína bruta no $49^{\circ}$ dia de idade. Houve efeito significativo $(p \leq 0,05)$ de tratamento sobre os níveis de proteína bruta no $35^{\circ}$ dia de idade das codornas. Codornas alimentadas com ração, colorífico e niacina suplementar apresenta-

Tabela 5. Matéria seca (MS), extrato etéreo (EE) e proteína bruta (PB), em porcentagem na matéria natural, da carne de peito, de coxa e sobrecoxa e carcaça de codornas japonesas machos aos 35 e 49 dias de idade ${ }^{(1)}$.

\begin{tabular}{|c|c|c|c|c|c|c|}
\hline Tratamento $^{(2)}$ & MS 35 & EE 35 & PB 35 & MS 49 & EE 49 & PB 49 \\
\hline & \multicolumn{6}{|c|}{ Carne de peito } \\
\hline Ração & $23,7 \pm 0,24$ & $0,56 \pm 0,06$ & $20,2 \pm 0,18$ & $24,0 \pm 0,10$ & $0,92 \pm 0,03 b$ & $20,6 \pm 0,11$ \\
\hline $\mathrm{R}+\mathrm{C}$ & $23,9 \pm 0,11$ & $0,53 \pm 0,03$ & $20,0 \pm 0,18$ & $23,8 \pm 0,16$ & $0,92 \pm 0,06 b$ & $20,4 \pm 0,10$ \\
\hline $\mathrm{R}+\mathrm{NS}$ & $23,6 \pm 0,22$ & $0,46 \pm 0,03$ & $19,9 \pm 0,09$ & $24,1 \pm 0,29$ & $1,42 \pm 0,07 \mathrm{a}$ & $20,6 \pm 0,30$ \\
\hline $\mathrm{R}+\mathrm{C}+\mathrm{NS}$ & $23,8 \pm 0,19$ & $0,52 \pm 0,11$ & $19,8 \pm 0,10$ & $24,2 \pm 0,05$ & $1,33 \pm 0,08 \mathrm{a}$ & $20,5 \pm 0,14$ \\
\hline $\mathrm{CV}(\%)$ & 1,86 & 28,19 & 1,63 & 1,63 & 12,51 & 1,97 \\
\hline \multirow[t]{2}{*}{ QM resíduo } & 0,1946 & 0,0213 & 0,1061 & 0,1530 & 0,0207 & 0,1633 \\
\hline & \multicolumn{6}{|c|}{ Carne de coxa e sobrecoxa } \\
\hline Ração & $20,7 \pm 0,18$ & $0,85 \pm 0,12$ & $17,2 \pm 0,09 b$ & $20,6 \pm 0,11$ & $0,72 \pm 0,03$ & $17,8 \pm 0,08$ \\
\hline $\mathrm{R}+\mathrm{C}$ & $20,6 \pm 0,22$ & $0,72 \pm 0,07$ & $17,6 \pm 0,12 b$ & $20,3 \pm 0,17$ & $0,90 \pm 0,10$ & $17,4 \pm 0,11$ \\
\hline $\mathrm{R}+\mathrm{NS}$ & $20,8 \pm 0,23$ & $0,79 \pm 0,09$ & $17,7 \pm 0,18 \mathrm{ab}$ & $20,6 \pm 0,21$ & $1,06 \pm 0,16$ & $17,5 \pm 0,19$ \\
\hline $\mathrm{R}+\mathrm{C}+\mathrm{NS}$ & $21,0 \pm 0,17$ & $0,64 \pm 0,09$ & $17,8 \pm 0,11 \mathrm{a}$ & $20,6 \pm 0,12$ & $0,97 \pm 0,08$ & $17,6 \pm 0,10$ \\
\hline $\mathrm{CV}(\%)$ & 2,19 & 28,09 & 1,64 & 1,73 & 24,95 & 1,62 \\
\hline \multirow[t]{2}{*}{ QM resíduo } & 0,2063 & 0,0445 & 0,0835 & 0,1269 & 0,0520 & 0,0813 \\
\hline & \multicolumn{6}{|c|}{ Carcaça } \\
\hline Ração & $24,0 \pm 0,20$ & $0,88 \pm 0,10$ & $15,8 \pm 0,15$ & $24,2 \pm 0,11$ & $2,08 \pm 0,12$ & $15,9 \pm 0,05$ \\
\hline $\mathrm{R}+\mathrm{C}$ & $24,0 \pm 0,46$ & $0,90 \pm 0,03$ & $15,9 \pm 0,21$ & $24,0 \pm 0,38$ & $2,48 \pm 0,17$ & $15,6 \pm 0,19$ \\
\hline $\mathrm{R}+\mathrm{NS}$ & $23,7 \pm 0,28$ & $0,96 \pm 0,08$ & $15,6 \pm 0,12$ & $24,6 \pm 0,13$ & $2,59 \pm 0,28$ & $15,6 \pm 0,12$ \\
\hline $\mathrm{R}+\mathrm{C}+\mathrm{NS}$ & $24,1 \pm 0,25$ & $0,88 \pm 0,03$ & $16,0 \pm 0,09$ & $24,5 \pm 0,15$ & $2,81 \pm 0,18$ & $15,8 \pm 0,12$ \\
\hline CV (\%) & 2,92 & 16,63 & 2,11 & 2,06 & 17,72 & 1,83 \\
\hline QM resíduo & 0,4908 & 0,0226 & 0,1112 & 0,2504 & 0,1947 & 0,0832 \\
\hline
\end{tabular}

(1)Carcaça com osso e sem cabeça, patas, pele, penas, vísceras, peito, coxas e sobrecoxas; médias seguidas por letras diferentes, diferem entre si pelo teste de Tukey a 5\% de probabilidade; média土erro-padrão da média. ${ }^{(2)}$ R: ração; C: colorífico (4,5\% da ração); NS: niacina suplementar (0,08\% da ração). 
ram maior teor de proteína bruta, na carne de coxa e sobrecoxa, do que codornas alimentadas com ração e com ração e colorífico (Tabela 5).

A maior deposição de proteína bruta $(17,8 \%)$ no tecido muscular da coxa e sobrecoxa das codornas tratadas com ração, colorífico e niacina suplementar, no 35 o dia de idade, ocorreu pela redução do teor de extrato etéreo $(0,64 \%)$, quando se comparou este tratamento ao tratamento com ração, que proporcionou $17,2 \%$ de proteína bruta e $0,85 \%$ de extrato etéreo. Silva et al. (2004) mencionaram a existência de correlação negativa entre os conteúdos de gordura e de proteína na carcaça de frangos.

No 35을 dia de idade, a carne de coxa e sobrecoxa das codornas tratadas com ração, colorífico e niacina suplementar apresentou $17,8 \%$ de proteína bruta, valor similar ao apresentado por codornas japonesas machos (17,9\%) com 35 dias de idade, obtido por Yalçin et al. (1995) (Tabela 5). Os valores médios de matéria seca ( $21,0 \%)$ e extrato etéreo $(0,64 \%)$, encontrados na carne de coxa e sobrecoxa das codornas tratadas com ração, colorífico e niacina suplementar, foram 16 e 86\% inferiores, respectivamente, aos valores de matéria seca (25\%) e extrato etéreo $(4,6 \%)$ obtidos por Yalçin et al. (1995). Genótipo, sexo, idade, entre outros fatores, podem causar essa diferença (Yalçin et al., 1995).

Não foi observado efeito significativo $(p>0,05)$ de tratamentos sobre os teores de matéria seca, extrato etéreo e proteína bruta, na carcaça (com osso e sem cabeça, patas, pele, penas, vísceras, peito, coxas e sobrecoxas) de codornas japonesas machos com 35 e 49 dias de idade (Tabela 5).

Kirkpinar \& Oguz (1995) encontraram 29,87\% de matéria seca, $21,53 \%$ de proteína bruta e $6,98 \%$ de extrato etéreo, na carcaça completa de codornas japonesas machos aos 35 dias de idade. Esses valores são bem superiores a $24,1 \%$ de matéria seca, $16 \%$ de proteína bruta e $0,88 \%$ de extrato etéreo, valores obtidos por codornas tratadas com ração, colorífico e niacina suplementar, no 35음 dia de idade.

As diferenças entre valores de composição química de carcaças, observadas em diferentes trabalhos, podem ser explicadas por fatores como dieta, idade, sexo, genótipo (Kirkpinar \& Oguz, 1995), bem como pelo uso de métodos distintos. Neste trabalho, no cômputo dos valores de extrato etéreo na carcaça, não foi incluída a pele, rica em gordura, que foi retirada no momento do abate das codornas.

\section{Conclusões}

1. A bixina do colorífico e a niacina suplementar promovem aumento do conteúdo de gordura da carne de peito de codornas japonesas machos com 49 dias de idade.

2. A bixina do colorífico e a niacina suplementar não reduzem os níveis de triglicerídeos e lipoproteínas de densidade muito baixa, no sangue de machos de codornas japonesas.

\section{Referências}

GOTTO JUNIOR, A.M. Triglyceride as a risk factor for coronary artery disease. The American Journal of Cardiology, v.82, p.2225, 1998.

GRIFFIN, H.D.; GODDARD, C.; BUTTERWITH, S.C. Control of lean and fat deposition in birds. In: BOORMAN, K.N.; BUTTERY, P.J.; LINDSAY, D.B. (Ed.). The control of fat and lean deposition. Oxford: Butterworth-Heinemann, 1999. p.231248.

HAMMAD, S.M.; SIEGEL, H.S.; MARKS, H.L. Total cholesterol, total triglycerides, and cholesterol distribution among lipoproteins as predictors of atherosclerosis in selected lines of Japanese quail. Comparative Biochemistry and Physiology, v.119, p.485-492, 1998.

HARDMAN, J.G.; LIMBIRD, L.E. (Ed.). Goodman \& Gilman's the pharmacological basis of therapeutics. $9^{\text {th }}$ ed. New York: McGraw-Hill, Health Professions, 1996. 1905p.

HERMIER, D. Lipoprotein metabolism and fattening in poultry. Journal of Nutrition, v.127, p.805-808, 1997.

KESSLER, A.M.; SNIZEK JÚNIOR, P.N. Considerações sobre a quantidade de gordura na carcaça do frango. In: MATTOS, W.R.S. (Org.). A produção animal na visão dos brasileiros. Piracicaba: Fealq, 2001. p.111-133.

KIRKPINAR, F.; OGUZ, I. Influence of various dietary protein levels on carcass composition in the male Japanese quail (Coturnix coturnix japonica). British Poultry Science, v.36, p.605-610, 1995.

LIMA, L.R.P.; OLIVEIRA, T.T.; NAGEM, T.J.; OLIVEIRA, M.G.A.; PINTO, A.S.; TINOCO, A.L.A.; STRINGHETA, P.C.; OLIVEIRA, M.L. Efeito de flavonóides (luteolina e apigenina) e corantes naturais (norbixina e bixina) do urucum sobre a atividade da lipase. Revista da Escola de Farmácia e Odontologia de Alfenas, v.21, p.29-36, 1999.

LIMA, L.R.P.; OLIVEIRA, T.T.; NAGEM, T.J.; PINTO, A.S.; STRINGHETA, P.C.; TINOCO, A.L.A.; SILVA, J.F. Bixina, norbixina e quercetina e seus efeitos no metabolismo lipídico de coelhos. Brazilian Journal of Veterinary Research and Animal Science, v.38, p.196-200, 2001.

NATIONAL RESEARCH COUNCIL (Washington, Estados Unidos). Nutrient requirements of poultry. $9^{\text {th }}$ ed. Washington: National Academy Press, 1994. 155p. 
ROSTAGNO, H.S.; ALBINO, L.F.T.; DONZELE, J.L.; GOMES, P.C.; FERREIRA, A.S.; OLIVEIRA, R.F.; LOPES, D.C. Tabelas brasileiras para aves e suínos: composição de alimentos e exigências nutricionais. Viçosa: UFV, Departamento de Zootecnia, 2000. 141p.

SANTOS, K.F.R.; OLIVEIRA, T.T.; NAGEM, T.J.; PINTO, A.S.; OLIVEIRA, M.G.A.; SOARES, J.F. Efeitos das associações de morina-ácido nicotínico e quercetina-ácido nicotínico no controle de lipídeos. Revista Brasileira de Análises Clínicas, v.31, p.5-7, 1999.

SILVA, D.J.; QUEIROZ, A.C. Análise de alimentos: métodos químicos e biológicos. 3.ed. Viçosa: UFV, 2002. 235p.

SILVA, J.H.V. da; SILVA, M.B. da; JORDÃO FILHO, J.; SILVA, E.L. da; ANDRADE, I.S.; MELO, D.A. de; RIBEIRO, M.L.G.;
ROCHA, M. do R. de F.; COSTA, F.G.P.; DUTRA JÚNIOR, W.M. Exigências de mantença e de ganho em proteína e energia em codornas japonesas (Coturnix coturnix japonica) na fase de 15 a 32 dias. Revista Brasileira de Zootecnia, v.33, p.1220-1230, 2004.

SOUZA, E.C.G. Efeito da bixina sobre os parâmetros séricos em ratos. 2001. 120p. Tese (Doutorado) - Universidade Federal de Viçosa, Viçosa.

UNIVERSIDADE FEDERAL DE VIÇOSA. SAEG: sistema de análises estatísticas e genéticas: versão 7.1. Viçosa: UFV, 1997. 150p.

YALÇIN, S.; OGUZ, I.; OTLES, S. Carcase characteristics of quail (Coturnix coturnix japonica) slaughtered at different ages. British Poultry Science, v.36, p.393-399, 1995.

$\overline{\text { Recebido em } 8 \text { de agosto de } 2005 \text { e aprovado em } 8 \text { de maio de } 2006}$ 